\title{
Teaching the Fundamentals of Remote Psychotherapy to Psychiatry Residents in the COVID-19 Pandemic
}

\author{
Anne E. Ruble ${ }^{1} \cdot$ Magdalena Romanowicz $^{2} \cdot$ Seamus Bhatt-Mackin ${ }^{3} \cdot$ David Topor $^{4} \cdot$ Aimee Murray $^{5}$ \\ Received: 18 August 2020 / Accepted: 10 May 2021 / Published online: 17 August 2021 \\ (C) This is a U.S. Government work and not under copyright protection in the US; foreign copyright protection may apply 2021
}

The COVID-19 pandemic required training programs to rapidly adopt remote therapy as in-office services are limited or prohibited; remote psychotherapy is unquestionably better than no clinical contact during a pandemic [1]. Although remote psychotherapy was not commonly used until the pandemic, evidence has been established for remote therapy for treatment of multiple psychiatric illnesses, including depression, social phobia, and panic disorder, particularly internetbased cognitive behavioral therapy [2]. While video sessions are particularly adapted to psychiatry due to psychiatry's greater emphasis on a history and mental status examination and less on the physical examination [3], residents may lack the skills and confidence required to perform remote therapy [4]. There is a particular concern regarding teaching residents to use remote therapy, which we define as therapy performed with the aid of video-based technology. We have chosen to discuss video-based therapy as residents train predominantly at academic institutions that accept insurance plans, many of which require video-based therapy for reimbursement, although this mandate is not based in evidence [1]. In addition to general psychotherapy skills, residents must learn to effectively treat certain populations via remote therapy: those experiencing psychosis, anxiety, or trauma. Thus, psychotherapy supervisors are tasked with learning new skills to conduct remote therapy sessions and teaching these skills to residents.

Anne E. Ruble

aruble@jhmi.edu

1 Johns Hopkins University School of Medicine, Baltimore, MD, USA

2 Mayo Clinic, Rochester, MN, USA

3 VA Mid-Atlantic MIRECC and Duke University, Durham, NC, USA

4 VA Boston Healthcare System and Harvard Medical School, Boston, MA, USA

5 University of Minnesota, Minneapolis, MN, USA
A particular challenge is teaching these skills to beginning residents who have minimal knowledge or experience of conducting psychotherapy in-office or remotely. Teachers of psychotherapy may practice any number of psychotherapies including supportive, cognitive-behavioral, and psychodynamic, so we have focused on shared fundamentals of teaching remote therapy in this article. Remote therapy education should include a combination of case-based psychotherapy supervision and didactic instruction about how to help residents become familiar with psychotherapy, particularly for those having limited or nonexistent office-based experience.

There is a particular need to educate residents to adapt traditional psychotherapy training skills such as establishing a therapeutic alliance with the patient. Teaching about therapeutic alliance also involves teaching residents other core features of psychotherapy including empathic listening, attending to boundaries, and matching treatment goals to the presenting problem [5]. These skills include development of the resident's "webside manner," a set of behaviors used to develop a therapeutic alliance in the virtual space with the patient [6], and "telepresence," the effect of "feeling present in the therapy room" with the therapist [7]. To assist supervisors in understanding their own skill set and comfort teaching remote psychotherapy, we developed a self-assessment (Table 1), discussion prompts, practice activities, and articles for discussion (Table 2) that can be used during psychotherapy supervision or in a psychotherapy seminar.

\section{Therapeutic Presence in Remote Therapy}

Telepresence is an important aspect of telehealth because it predicts the strength of the therapeutic relationship [8]. Several strategies can be used to create therapeutic presence. To increase engagement in the virtual realm, residents can be directed to orient the patient to this modality. Residents should consider that it can be uncomfortable to be in a virtual world, especially when a patient can see themselves on video. 
Table 1 Self-assessment of conducting psychotherapy via remote sessions

\begin{tabular}{|c|c|c|c|c|c|}
\hline & $\begin{array}{l}\text { Strongly } \\
\text { Disagree }\end{array}$ & Disagree & $\begin{array}{l}\text { Neither } \\
\text { Agree nor } \\
\text { Disagree }\end{array}$ & Agree & $\begin{array}{c}\text { Strongly } \\
\text { Agree }\end{array}$ \\
\hline $\begin{array}{l}\text { I have the knowledge } \\
\text { needed to operate the } \\
\text { technology for remote } \\
\text { sessions. }\end{array}$ & & & & & \\
\hline $\begin{array}{l}\text { I feel comfortable doing } \\
\text { psychotherapy via remote } \\
\text { sessions. }\end{array}$ & & & & & \\
\hline $\begin{array}{l}\text { I believe psychotherapy via } \\
\text { remote sessions is } \\
\text { effective. }\end{array}$ & & & & & \\
\hline $\begin{array}{l}\text { I feel comfortable teaching } \\
\text { trainees best practices to } \\
\text { do remote session } \\
\text { psychotherapy. }\end{array}$ & & & & & \\
\hline
\end{tabular}

What are additional knowledge, skills, and abilities I need to conduct psychotherapy via remote sessions?

What is my action plan to gain this knowledge, skills, and ability? 
Table 2 Discussion prompts and articles for discussion

General
$\begin{gathered}\text { - Complete self-assessment as a group } \\ \text { overview of }\end{gathered}$
teletherapy
Discuss importance of reviewing teaching institution's policies
regarding therapy through risk management or telemedicine offices
theoretical orientations as well as phone and video

Telepresence - Practice orienting the person to the virtual environment (tell them about what to expect for eye contact, if you will be typing notes, what might be happening if you are quiet, etc.).

- Practice talking about an emotionally positive experience. Ask if the conversation seemed to make the other person almost "forget" they were in a virtual environment.

- Practice expressing emotions and using nonverbal forms of communication. Ask if the interaction seemed natural. Was something missing?

- Check in to see if anything seemed distracting from the interaction. Ask if there were there any behaviors, noises, visual items that pulled away from being present. Consider how close or far from the screen one should be to optimize the experience of presence while being close enough to be heard. Are all computer based distractions closed (e.g., email, chat, etc.)?

- Was there something missing from the interaction? (Although an in person interaction cannot be exactly duplicated, something might be fine-tuned to more closely assimilate an in-person environment).

Boundaries $\quad$ Discuss whether residents have done therapy in an office setting or only virtually to assess their thoughts on similarities/differences, comfort/discomfort with each setting.

- Plan and problem solve decisions to see patients only within business hours or flex hours in certain situations

- Have residents consider and discuss their use of video calls prior to COVID-19 and after COVID-19 and ways to ensure that calls are professional and not social in nature.

- Role-play a discussion with a patient about how to ensure the setting is private and any personal objects are outside the view of the webcam.

- Consider and discuss • safety planning and role play how to conduct these discussions remotely. $\begin{array}{cc}\text { Therapeutic } & \text { Role-play a conversation with a patient to generate treatment goals to } \\ \text { alliance } & \text { practice making goals less complex, and more achievable and col- }\end{array}$ laborative

- Discuss steps to increase therapeutic presence such as positioning of patient and therapist in the monitor and how one would facilitate this discussion

- Reinforce self-activation and assertiveness on the part of the patient and role play how this would be done in a session

Transference - Broadly define transference both in the context of psychodynamic and non-dynamic therapies to ensure that all residents feel comfortable with the terminology used in the course of didactics.

- Have residents discuss differences and similarities in transferences developed in online and offline settings.

- Role-play various transference interpretations that might be used in online setting. Consider discussing handling positive and negative transference in different therapies: CBT, supportive and psychodynamic.

Special - Discuss the absolute contraindications to online therapy. Use case populations examples to illustrate specific challenges that may arise with specific patients while receiving online services.

- Have residents consider providing online therapy for special populations of patients such patients with psychotic symptoms or patients with personality disorder diagnosis.
- Shore JH, Yellowlees P, Caudill R, Johnston B, Turvey C, Mishkind M, et al. Best Practices in Videoconferencing-Based Telemental Health April 2018. Telemed J E Health 2018 11;24(11):827-832.

- Markowitz JC, Milrod B, Heckman TG, Bergman M, Amsalem D, Zalman H, et al. Psychotherapy at a Distance. Am J Psychiatry 2020 -09-25:appiajp202020050557.

- Hilty D, Randhawa K, Maheu M, McKean A, Pantera R. Therapeutic Relationship of Telepsychiatry and Telebehavioral Health:

Ideas from Research on Telepresence, Virtual Reality and Augmented Reality.

Psychology \& Cognitive Sciences 2019;5(1):14-29.

Drum KB, Littleton HL. Therapeutic boundaries in telepsychology: Unique issues and best practice recommendations. Prof Psychol Res Pr 2014 Oct;45(5):309-315.

Norwood C, Moghaddam NG, Malins S, Sabin-Farrell R. Working alliance and outcome effectiveness in videoconferencing psychotherapy:

A systematic review and noninferiority meta-analysis. Clin Psychol Psychother 2018 Nov;25(6):797-808.

- Migone, P. Psychoanalysis on the internet: A discussion of its theoretical implications for both online and offline therapeutic technique. Psychoanalytic Psychology, 30(2), 281-299.

- Kocsis BJ, Yellowlees P. Telepsychotherapy and the therapeutic relationship: Principles, advantages, and case examples. Telemedicine and e-Health 2018;24(5):329. 
Starting with asking about the potential discomfort, and normalizing this reaction, can help patients settle into the experience. If eye contact is an important part of cultural engagement for the patient, explain the difference in eye contact on camera vs. face-to-face therapy. The therapist can explicitly tell a patient, "This is what my eyes look like when I am looking at you on the screen, and this is what they look like if I am looking into the camera." If the therapist looks away, they might want to share what is happening, because the patient cannot see the full environment. For example, if the therapist is looking away to take notes, the patient may not know what the therapist is doing, and it may feel as if the therapist is not attending to the patient, even though that is the purpose of taking notes. If there is a noise in the background, the therapist may take time to explain the source, as this knowledge will likely decrease the distraction. Orienting the patient means bringing them into the therapist's space verbally.

Discussion of emotions with a patient can also lead to an increased sense of therapeutic presence [9]. Focusing on emotional topics, which tends to come organically in therapy, will likely increase the sense of presence. Spending some time discussing positive emotional experiences at the beginning of the relationship can build engagement. It is also important to consider therapeutic behaviors that typically take place in person (nonverbal expression of empathy, a handshake, etc.) and how these may need to be replaced with video, words, and nonverbal communication [7]. It is likely the therapist will need to amplify therapeutic behaviors that would typically happen during an in-person interaction. For example, amplifying hand and facial gestures can show interest in what the patient is saying and convey empathy [10].

Residents should be taught to be aware of how an online environment magnifies extraneous sounds, images, and movements. In other words, supervisors should ask residents, "What environmental elements would you like to minimize to indicate 'presence' during your session?" Virtual environments heighten pen tapping, noise from jewelry scraping, chair rocking, or a microphone too close to a mouth. Some of these factors can be visually distracting, including glare from glasses or certain prints on clothing, or being too close or too far away from the camera [7]. Thus, even what is on the screen can add to the distraction quotient. A few simple changes can reduce distractions. These changes can include turning off email, distancing oneself from the keyboard to reduce the temptation to use other options on the computer, and minimizing or hiding your own image (if possible) [1]. Distancing oneself from the screen enough to see more of the person while still optimizing the closeness needed for sound quality can help duplicate the in-person presence [1].

For residents learning telehealth, practicing with a supervisor or a peer in the environment they plan to provide these services in, can be critical. This practice will afford an opportunity to check in with someone about the resident's telepresence and receive feedback on areas to improve. The telepresence discussion prompts (Table 2) may be reviewed in a didactic or role-play, either one on one with a psychotherapy supervisor or in a seminar setting.

\section{Developing Awareness of Potential Boundary Concerns in Remote Therapy}

Boundary issues in remote therapy arise from two factors: the possibility of having a more flexible frame may prompt more casual interactions and behaviors with the patient, particularly in that video-based communication is often used with family and friends, and an assumption that the physical distance makes the therapeutic relationship immune from boundary crossings and violations [11]. Boundary crossings are considered minor departures from typical therapeutic practices such as giving a patient a hug at a final session or attending a patient's graduation after having been invited; boundary crossings may be therapeutic, neutral, or harmful [4]. Boundary crossings that include ethical violations, such as having a sexual relationship with a patient, are always considered harmful [4, 12].

To maintain boundaries, remote therapy sessions and patient communication should take place during typical working hours [11]; if there are compelling reasons for a change for particular patients or situations, residents should be encouraged to talk through their plan with supervisors in advance of making these arrangements with patients. This will help patients feel that the relationship is predictable and dependable, and avoids miscommunications (e.g., a therapy session newly taking place in the evening outside of normal meeting times may convey a level of intimacy that may evoke a therapy session seeming like a dinner with a friend or potential romantic partner or be too threatening/invasive, depending on the patient). Residents should maintain awareness if sessions with any particular patients begin to seem less formal and should seek supervision.

Sessions outside of normal business hours or when the resident is away from the clinic may also contribute to trainee burnout and should be discussed with therapy supervisors. There may be valid reasons to shift a resident's therapy schedule (e.g., childcare), but it is recommended that residents discuss this plan with supervisors for guidance. Residents need to have continued awareness that they have appropriate licensure to practice telemedicine for their location and the location of the patient [13]; although restrictions have loosened during the pandemic, it is unclear how long these relaxed practice restrictions will remain in effect. Supervisors should advise residents of appropriate hospital resources that address these concerns.

The physical environment of both the patient and the resident should be considered; both dress and environment should be similar to what is appropriate for a physical office, and 
therapy should be conducted in a private location that is culturally sensitive. This can include displaying an array of ethnically diverse art or symbols supporting LGBTQ rights. A resident should be advised by the supervisor to consider removing personal items from the camera's view and have a conversation with patients about personal objects in the view of the camera in advance of the session and encourage patients to do the same - this minimizes involuntary patient disclosures. Residents should express willingness to problem-solve with a patient about finding an appropriate private location and webcam setup and can discuss this with supervisors and in seminar as recommended in the prompts in Table 2.

\section{Building a Therapeutic Alliance in Remote Therapy}

The cultivation of a strong therapeutic alliance is correlated with positive outcomes in psychotherapy [14] and is an important aspect of teaching psychotherapy to residents. There are some suggestions that come from published clinical reports and empirical work done on the cultivation of a therapeutic alliance in psychotherapy using remote therapy. The suggestions are appropriate for junior therapists learning to do psychotherapy for the first time remotely and for their teachers and clinical supervisors. Prompts for guiding this discussion are found in Table 2.

The therapeutic alliance can be understood in general as "an emergent quality of mutual collaboration and partnership between the therapist and the client" [15]. The alliance has three commonly identified components: (1) agreement between therapist and patient on the goals of treatment, (2) agreement between therapist and patient on the tasks involved in reaching those goals, and (3) a positive bond between therapist and patient [14].

A meta-analytic review of 295 independent studies covering more than 30,000 patients shows a robust relationship between alliance and outcomes of therapy [15]. In this review, 23 independent studies including 1178 patients were in a videoconferencing format and the relationship between alliance and clinical outcome was approximately the same. Conversely, a meta-analytic study comparing therapeutic alliance between face-to-face and videoconferencing found that alliance was inferior in the videoconferencing format [16]. When considering that literature, it is important to note that the therapy conducted in those studies was not happening during a pandemic when the parties involved may not have any choice but to work through videoconferencing, and the study therapists were not novices in learning psychotherapy. The current pandemic calls for new ways of working with patients and will yield new learning; resident psychotherapists can take advantage of the shared situation to learn to collaborate with their patients. Supervisors should encourage residents to continue to discuss setup of video visits in supervision and seminars and how setup may change during the course of therapy.

Another area to consider in terms of the therapeutic alliance includes populations with less access to digital services. This includes patients without access to internet devices or data plans to access the online therapy platform [17]. These patients may have limited access to video; it may be of benefit to have an office in the clinic for remote therapy. A patient could come to residents' clinic for an initial session and be set up for video visit by office staff, with the resident doing remote therapy from another office. This would allow residents to "meet" a new patient while maintaining physical distancing. This type of setup could also be used intermittently along with telephonic sessions to build therapeutic alliance as remote therapy proceeds. It is also possible to do a hybrid visit, with part of the session in person and part remote. This may be useful for an emergent session and can be suggested to and discussed with residents.

\section{Remote Therapy Recommendations in Special Populations}

Almost any patient can be seen via video conferencing [18] The absolute contraindications are patients refusing to attend online sessions and patients who are demonstrating behaviors that are dangerous to themselves or others [18]. Several groups of patients require specific considerations: those experiencing psychosis, personality vulnerabilities, those with autism spectrum disorders, children and teenagers, and those with a significant history of trauma.

Patients with psychosis may have paranoid thoughts about computers or telephones. However, a patient with psychotic symptoms might also feel safer when the therapist is not in the room. Overall, telepsychiatry has been well tolerated by patients with psychotic symptoms and is known to reduce anxiety in this patient population [19]. One consideration for collaborative care is to ask patients experiencing psychosis if they would prefer to focus the camera away from them. Supervisors should check in with residents about how remote sessions are progressing with any patient experiencing psychosis; a combination of phone, video, and office-based sessions may work best if the patient is uncomfortable with remote therapy.

Many high functioning patients with autism spectrum disorders enjoy computers and use various online groups for support. A hybrid approach may be considered after a therapeutic relationship is established online [20].

Children might feel more comfortable with sessions at home, and the therapist might get a more accurate picture of a child's behaviors in their home environment. Teenagers spend a considerable time online in general; online therapy 
allows them to be independent from their parents as parents would not need to drive them to appointments [21].

Patients having significant childhood abuse histories and victims of sexual abuse or rape may feel safer with an online modality and a hybrid approach with gradual exposure to in person meetings. Data show that online sessions with cognitive processing therapy and CBT are non-inferior to in-person delivery of either modality. Virtual therapy allows for increased privacy, reduction of stigma, and all the comforts associated with teletherapy [22].

More research is needed in the area of treating patients with personality disorders remotely. Convenience may allow for a greater number of sessions, an increased sense of comfort, and "therapist presence." A hybrid approach might be necessary for some patients with exclusively in person sessions for others due to diminished capacity for symbolization without the physical presence of the therapist in the office. For a patient whose illness has been formulated to include a personality disorder, setting boundaries and maintaining a consistent frame are as important for remote therapy as they are for office-based therapy [23], and appropriate supervision should be sought by residents.

\section{Conclusions}

Teletherapy is an extremely important tool to maintain the well-being of patients during the pandemic and has the benefit of establishing and maintaining care for those experiencing psychiatric illness and distress. Many articles have addressed teaching clinicians who are experienced in face-to-face sessions and are moving to a teletherapy model and best practices therein [13], but few, if any, have considered how to help supervisors teach psychiatry residents basic skills in psychotherapy in a purely virtual environment. Training of psychiatric residents in teletherapy and support of psychotherapy supervisors during this challenging time is vital for the success of ongoing efforts to maintain regular therapy sessions with patients and to ensure access to care as in-office services are limited or impossible.

Acknowledgements The authors wish to acknowledge AADPRT Psychotherapy Committee who helped with development of this project. Prior version of the article was circulated among members of the committee.

\section{Declarations}

Ethics approval IRB review not applicable

Disclosures M.R. receives grant funding from the Mayo Foundation Departmental Small Grant Program and the Palix Foundation. A.R., S.B.M., D.T. and A.M. have no biomedical conflicts of interest to declare.

\section{References}

1. Markowitz JC, Milrod B, Heckman TG, Bergman M, Amsalem $\mathrm{D}$, Zalman H, et al. Psychotherapy at a distance. Am J Psychiatry. 2020;178:240-6. https://doi.org/10.1176/appi.ajp. 2020.20050557.

2. Hedman E, Ljótsson B, Lindefors N. Cognitive behavior therapy via the Internet: a systematic review of applications, clinical efficacy and cost-effectiveness. Expert Rev Pharmacoecon Outcomes Res. 2012;12(6):745-64.

3. Kannarkat JT, Smith NN, McLeod-Bryant SA. Mobilization of telepsychiatry in response to COVID-19-moving toward 21st century access to care. Admin Pol Ment Health. 2020;47(4):489-91.

4. Smith D, Fitzpatrick M. Patient-therapist boundary issues: an integrative review of theory and research. Prof Psychol Res Pract. 1995;26(5):499-506.

5. Plakun EM, Sudak DM, Goldberg D. The Y model: an integrated, evidence-based approach to teaching psychotherapy competencies. J Psychiatr Pract. 2009;15(1):5-11.

6. McConnochie KM. Webside manner: a key to high-quality primary care telemedicine for all. Telemed J E Health. 2019;25(11): $1007-11$.

7. Hilty DM, Randhawa K, Maheu MM, McKean AJS, Pantera R. Therapeutic relationship of telepsychiatry and telebehavioral health: Ideas from research on telepresence, virtual reality and augmented reality Psychol Cogn Sci Open J. 2019; 5(1): 14-29.

8. Haddouk L, Bouchard S, Brivio E, Galimberti C, Trognon A. Assessing presence in videconference telepsychotherapies: a complementary qualitative study on breaks in telepresence and intersubjectivity co-construction processes. Annu Rev Cyberther Telemed. 2018;16:118-23.

9. Bouchard S, Dumoulin S, Michaud M, Gougeon V. Telepresence experienced in videoconference varies according to emotions involved in videoconference sessions. Stud Health Technol Inform. 2011;167:128-32.

10. Maheu MM, Drude KP, Hertlein KM, Hilty DM. A framework of interprofessional telebehavioral health competencies: Implementation and challenges moving forward. Acad Psychiatry. 2018;42(6):825-33.

11. Drum KB, Littleton HL. Therapeutic boundaries in telepsychology: unique issues and best practice recommendations. Prof Psychol Res Pract. 2014;45(5):309-15.

12. Gutheil TG, Gabbard GO. The concept of boundaries in clinical practice: theoretical and risk-management dimensions. Am J Psychiatry. 1993;150(2):188-96.

13. Shore JH, Yellowlees P, Caudill R, Johnston B, Turvey C, Mishkind $\mathrm{M}$, et al. Best practices in videoconferencing-based telemental health April 2018. Telemed J E Health. 2018;24(11): 827-32.

14. Horvath AO. Research on the alliance: knowledge in search of a theory. Psychother Res. 2018;28(4):499-516.

15. Flückiger $\mathrm{C}$, Del Re AC, Wampold BE, Horvath AO. The alliance in adult psychotherapy: a meta-analytic synthesis. Psychotherapy. 2018;55(4):316-40.

16. Norwood C, Moghaddam NG, Malins S, Sabin-Farrell R. Working alliance and outcome effectiveness in videoconferencing psychotherapy: a systematic review and noninferiority meta-analysis. Clin Psychol Psychother. 2018;25(6):797-808.

17. Torous J, Jän Myrick K, Rauseo-Ricupero N, Firth J. Digital mental health and COVID-19: using technology today to accelerate the curve on access and quality tomorrow. JMIR Ment Health. 2020;7(3):e18848.

18. Kocsis BJ, Yellowlees P. Telepsychotherapy and the therapeutic relationship: principles, advantages, and case examples. Telemed e-Health. 2018;24(5):329-34. 
19. Sharp IR, Kobak KA, Osman DA. The use of videoconferencing with patients with psychosis: a review of the literature. Ann General Psychiatry. 2011;10(1):14.

20. Boada L, Parellada M. Seeing the doctor without fear: www.doctortea.org for the desensitization for medical visits in autism spectrum disorders. Revista de psiquiatria y salud mental. 2017;10(1):28-32.

21. Pakyurek M, Yellowlees P, Hilty D. The child and adolescent telepsychiatry consultation: can it be a more effective clinical process for certain patients than conventional practice? Telemed eHealth. 2010;16(3):289-92.

22. Morland LA, Mackintosh M, Rosen CS, Willis E, Resick P, Chard $\mathrm{K}$, et al. Telemedicine versus in-person delivery of cognitive processing therapy for women with posttraumatic stress disorder: a randomized noninferiority trial. Depress Anxiety. 2015;32(11): 811-20.

23. Morland LA, Poizner JM, Williams KE, Masino TT, Thorp SR. Home-based clinical video teleconferencing care: Clinical considerations and future directions. Int Rev Psychiatry. 2015;27(6): 504-12.

Publisher's Note Springer Nature remains neutral with regard to jurisdictional claims in published maps and institutional affiliations. 